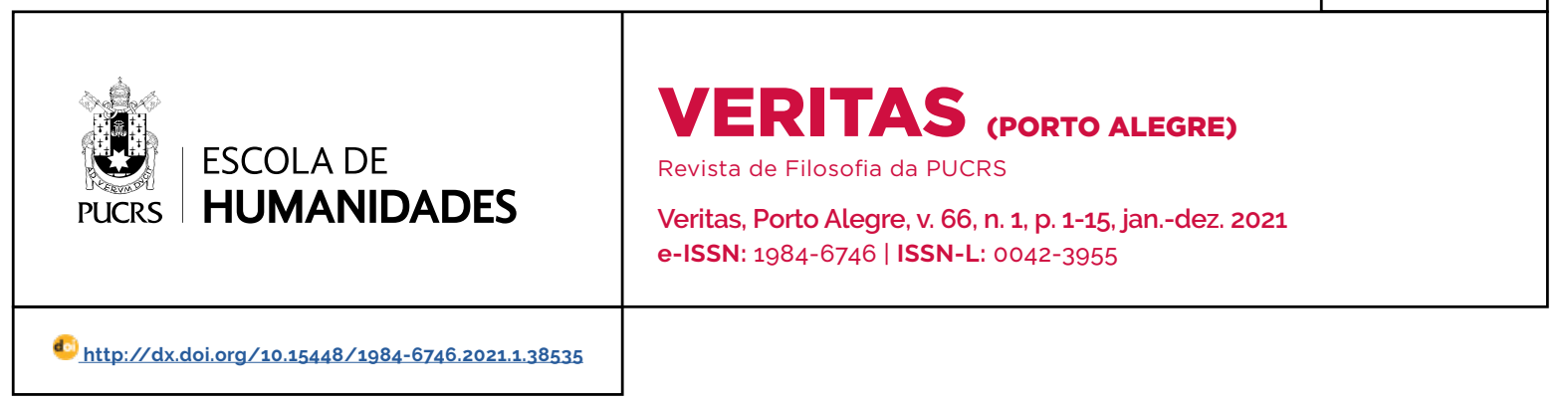

SEÇÃO: VARIA

\title{
O problema do amor e da distância em Anne Carson
}

\author{
The problem of love and distance in Anne Carson \\ El problema del amor y la distancia en Anne Carson
}

\author{
Rafael Saldanha ${ }^{1}$ \\ orcid.org/0000-0001-6315-9228 \\ rafaelsaldanha@gmail.com
}

Recebido em: 7 out. 2020 .

Aprovado em: 19 out. 2021

Publicado em: 21 jun. 2021

\section{(c) (i)}

Artigo está licenciado sob forma de uma licença Creative Commons Atribuição 4.0 Internacional.
Resumo: O presente trabalho tem como objetivo apresentar a rearticulação do problema do amor na obra da classicista e poeta Anne Carson. Em seu livro Eros, the bittersweet, Carson realiza uma reconstrução do problema do amor na tradição helênica. A operação, porém, não se restringe a uma mera reconstrução histórica, visto que as elaborações conceituais da autora acabam pondo o problema do amor como um tipo de situação que tem sua força justamente na transcendência das condições particulares. Analisaremos, portanto, como Carson concebe os contornos da dinâmica do amor como uma relação entre amante, amado e a distância entre eles, a partir das obras de Safo de Lesbos. Em seguida, discutiremos no artigo como, a partir dessa concepção da relação amorosa, a autora elabora, por meio de uma leitura do diálogo Fedro de Platão, os desdobramentos do problema do amor na questão da composição dos sujeitos (ou seja, redefinindo "o que é um sujeito" a partir do problema do amor) e nas experiências do tempo e do espaço. No fim, procuramos demonstrar como a obra de Carson nos fornece uma visão renovada do problema do amor.

Palavras-chave: Amor. Eros. Anne Carson. Platão.

Abstract: This work aims to evaluate the rearticulation of the problem of love in the work of the classicist and poet Anne Carson. In her book Eros, the bittersweet, Carson carries out a reconstruction of the problem of love in the Hellenic tradition. The operation, however, is not restricted to a mere historical reconstruction, since the author's conceptual elaborations end up placing the problem of love as a type of situation that has its strength precisely in the transcendence of particular conditions. We will analyze, therefore, how Carson conceives the contours of the dynamics of love as a relationship between lover, loved one and the distance between them on the basis of the works of Safo of Lesbos. Then we will discuss in the article how, from this conception of the love relationship, the author elaborates, through a close reading of Plato's Phaedrus dialogue, the unfoldings of the problem of love in the question of composition of subjects (that is, redefining 'what is a subject' from the problem of love) and in the experiences of time and space. In the end, we will believe we have shown how Carson's work gives us a renewed vision of the problem of love. Keywords: Love. Eros. Anne Carson. Plato.

Resumen: Este trabajo pretende evaluar la rearticulación del problema del amor en la obra de la clasicista y poeta Anne Carson. En su libro Eros, the bittersweet, Carson lleva a cabo una reconstrucción del problema del amor en la tradición helénica. La operación, sin embargo, no se limita a una mera reconstrucción histórica, ya que las elaboraciones conceptuales del autor terminan por situar el problema del amor como un tipo de situación que tiene su fuerza precisamente en la trascendencia de las condiciones particulares. Analizaremos, por tanto, cómo Carson concibe los contornos de la dinámica del amor como una relación entre amante, amado y la distancia entre ellos de las obras de Safo de Lesbos. A continuación, en el artículo se discutirá cómo, a partir de esta concepción de la relación amorosa, la autora elabora, a través de una lectura atenta del diálogo Fedro de Platón, los desdoblamientos del problema del amor en la cuestión de la composición de los sujetos (es decir, la redefinición de "lo que es un sujeto" a partir del problema del amor) y en las experiencias del tiempo y del espacio. Al final, creeremos haber 
demostrado cómo el trabajo de Carson nos da una visión renovada del problema del amor.

Palabras clave: Amor. Eros. Anne Carson. Platón.

Gostaríamos de desenvolver aqui a noção de amor elaborada por Anne Carson em seu Eros, the bittersweet que foi publicado em 1986. ${ }^{2}$ Se esse livro nos interessa, é por nos apresentar um caminho para voltar a pensar o problema do amor na filosofia. Um problema que, acreditamos, tem estado meio esquecido nos círculos filosóficos, mas que não deixou de ser elaborado em disciplinas próximas. Na psicanálise, por exemplo, as relações entre amor, desejo e sexo são um tema central. ${ }^{3}$ Nas ciências sociais, por sua vez, não faltarão investigações que procurem analisar o sentido do amor na vida social e suas inúmeras variações culturais. ${ }^{4}$ E na filosofia? Bem, na filosofia parece que, salvo algumas exceções pontuais ou marginais 5 (que se tornam ainda menores, se considerarmos a longevidade e a amplitude da história da filosofia), somos condenados a repetir a pergunta de Fedro, no início de O banquete: "não é estranho, Erixímaco, que para outros deuses haja hinos e peãs, feitos pelos poetas, enquanto que ao amor todavia, um deus tão venerável e tão grande, jamais um só dos poetas que tanto se engrandeceram fez sequer um encômio?" (PLATÃO, 2016b, 177a-177b) É estranho a ponto de soar quase premonitório que, já nas origens do pensamento filosófico, o problema do amor seja apresentado como uma discussão marginalizada. Mesmo o fato de Platão - o filósofo mais influente da história da filosofia - trazer o tema para o centro de seu pensamento em diálogos como o Fedro e O banquete, ${ }^{6}$ parece não ser suficiente para retirar o amor dessa posição descrita pelo personagem Fedro em O banquete. O livro de Carson nos interessa, portanto, por restituir a dignidade filosófica do problema do amor.
Dito isso, neste trabalho iremos apresentar a posição da autora e comentar as implicações da sua concepção de amor. Mas isso não será feito por uma análise do conteúdo do seu texto. O que nos interessa, até para marcar a especificidade da leitura carsoniana, é destacar também como ela produz essa leitura, algo que aparece sobretudo na forma peculiar como ela lê o diálogo platônico Fedro. A autora não se satisfaz em reconstruir as teses elaboradas no Fedro, mas procura rearranjar os próprios acontecimentos do diálogo afim de iluminar certos temas e problemas que antes não apareciam com tanta clareza. Com esse gesto, porém, a autora parece também dramatizar as próprias teses que constrói em sua releitura do Fedro, já que um dos elementos que é posto em destaque é a conexão intima entre o problema do amor e a transformação do amor em objeto do pensamento.

Em primeiro lugar, é preciso destacar que o livro de Carson se apresenta como uma elaboração dos traços gerais do problema do amor na antiguidade. A análise desse tópos, que vai da poesia de Safo aos diálogos de Platão, não se limita, porém, a apenas descrever um tipo de sentimento que existiria na cultura grega clássica. O que Carson procura fazer em sua reconstrução histórica é mostrar a emergência de um campo de problemas relacionado à experiência do amor. Se essa reconstrução precisa ser histórica é porque, como mostra a autora, a aparição do amor como problema na cultura grega estaria intimamente ligada às transformações no mundo grego que ocorreram nesse período. Mas é justamente por isso que o livro, apesar de possuir um certo recorte histórico, vai além de uma reconstrução de um passado acabado. O amor não é simplesmente um pensado como um fenômeno estritamente histórico, mas como um acontecimento que aspira superar as condições da finitude.

\footnotetext{
2 Esse livro é uma versão reduzida e transformada em ensaio de sua tese de doutorado.

3 Isso inclusive aparece na maneira como o conceito de "transferência" é pensado nos termos do problema do amor. Cf. Freud (2010, 2013) e Lacan (1992).

4 Cf. Bauman (2004) e Eva Ilouz (2012)

5 Ainda que o problema do desejo, do sexo, da paixão e da amizade apareçam com frequência na história da filosofia, é curioso que o problema do amor costume aparecer sempre submetido a esse campo de problemas, quase como uma nota de rodapé, um corolário que se deve mencionar sem que se dê muita centralidade a ele.

6 Como o próprio Sócrates afirma no início de O banquete, trata-se do único tema que ele efetivamente conhece. É por isso que, na hora de decidir o tema a ser discutido, Sócrates afirma sem hesitar que "ninguém contra ti votará, ó Eriximaco le sua proposta de discutir o amor]. [.... Pois nem certamente me recusaria eu, que afirmo em nada mais ser entendido senão nas questões de amor" (PLATÃO, 2016b, 177d). Cf. Armand D'Angour (2019).
} 
É por isso que, ainda que seja possivel ler este livro como uma obra que apenas reconstrói o conceito de amor em um determinado periodo histórico, acredito que isso subdimensiona tanto a obra de Carson como também as implicações conceituais que aparecem em sua reconstrução do problema do amor. A primeira forma de evitar essa leitura meramente historicizante é lembrar que esse campo de problemas elaborado na antiguidade continua aparecendo como uma questão para nós - ainda que alterada pelo tempo. Isso é possivel, pois o tipo de experiência ali descrita não corresponde a um sentimento que existe em uma cultura específica. O amor, tal como discutido por Carson, é uma experiência que, em sua própria essência, põe em questão as distinções entre particular e universal, pela maneira como ele lida ao mesmo tempo com o tempo e a eternidade (o que explicaria a capacidade dos amantes transcenderem o momento em que se dá seu encontro). Se a obra de Carson se apresenta como histórica, portanto, é justamente para tentar entender o aparecimento de um tipo de evento que tem como característica se desprender de seu solo finito e histórico em direção a uma dimensão infinita e eterna.

Essa experiência do amor é resumida pela autora já no início do livro, a partir de dois elementos que aparecem na poesia de Safo. Em primeiro lugar, Eros (ou seja, o amor)7 é sempre agridoce ( $ү \lambda$ uкúтাıроv), como vemos no fragmento 130: "Eros de novo - o solta membros - me agita, doce-amarga lagridoce] inelutável criatura" (SAFO DE LESBOS, 2011, p. 86). Mas que tipo de experiência é essa? Trata-se, a principio, da experiência de desejar aquilo que não se tem. Que haja um componente de amargor nessa experiência não surpreende. Afinal, como na fome, aquilo que nos falta não deixa de provocar incômodo, sofrimento. Mas o que faz o amor aparecer como uma questão - o que o torna esquisito - é que essa experiência tem algo de gostoso, de agradável. No amor, o próprio aspirar ao objeto amado tem algo que é saboreado, de modo que o amor seria uma espécie de falta que também nos preenche - mas com o quê?

É para dar conta dessa confusão entre o doce e o amargo que Carson destaca o segundo elemento que delimitaria a estrutura da experiência do amor: seu caráter triangular. No fragmento 31, Safo desenha essa estrutura como sendo composta por um amante, um amado e um obstáculo. O que é importante notar, porém, é que o obstáculo não é causa do fracasso, mas é condição da própria experiência agridoce de Eros. Eis o fragmento:

\author{
Parece-me ser par dos deuses ele, \\ o homem, que oposto a ti \\ senta e de perto tua doce \\ fala escuta
}

e tua risada atraente. Isso, certo,

no peito atordoa meu coração;

pois quando te vejo por um instante, então

falar não posso mais,

\begin{abstract}
mas se quebra minha lingua, e ligeiro fogo de pronto corre sob minha pele, e nada veem meus olhos, e zumbem meus ouvidos, e água escorre de mim, e um tremor de todo me toma, e mais verde que a relva estou, e bem perto de estar morta pareço eu mesma (SAFO DE LESBOS, 2011 p. 105-106)
\end{abstract}

O que faz essa estrutura ser necessária - e que não torna o obstáculo um fracasso, mas sim uma condição - é que o objeto desejado só aparece enquanto desejado na medida em que ele é, em algum sentido, separado de nós. É a presença de um limite que o torna visível como

\footnotetext{
7 É preciso ter em conta que as discussões, as menções e os elogios ao amor não deixam de ser comentários que apresentam um equivoco entre a figura mitica de Eros e a experiência do amor. Algo que se pode observar no próprio O Banquete, que tem nos seus dois primeiros discursos (de Fedro e Pausânias) elogios aos deuses, para só em seguida a discussão tratar do sentimento do amor. Há portanto, no livro de Carson, uma ambiguidade no uso da palavra "eros", entre um uso que se refere à figura mítica e outro que indica a experiência amorosa (marcada pela minúscula). Ainda que a ênfase de qual sentido predomina no uso do termo possa ser apontado pelo uso de uma grafia maiúscula (para se referir ao deus) ou minúscula (para se referir à experiência), é importante manter em mente que mesmo com as ênfases, ambos os sentidos estão presentes no uso do termo.
} 
objeto amoroso. A principio pode-se pensar que isso não se diferencia muito de outras situações em que desejamos algo. Se, porém, acredita-se que o amor não é um desejo qualquer, é porque essa separação não diz respeito apenas a um corpo que é diferente do meu. O que está distante do amante, e que produz uma das angústias que geralmente consomem os amantes, é a opacidade do desejo do outro. Caso seu desejo fosse como o do amante, nenhum mistério existiria, os corpos dos amantes se atrairiam e tudo poderia ser resolvido mais facilmente. O limite que se encontra na experiência amorosa (e que aparece por meio das incertezas do amante) é um sinal de uma distância entre o desejo do amante e o do amado.

No caso do fragmento citado acima, o objeto do amor de Safo aparece apenas a partir do homem com quem ela conversa ("que oposto a ti / senta e de perto tua doce / fala escuta"). A amada não fala com a Safo, não direciona seus encantos a ela, mas sim ao homem. Como não é ela para quem sua amada se dirige, e sim para o homem com quem fala, transparece uma distância e um possivel desencontro entre o desejo de amante e amada. Safo é capaz de perceber a amada - e de sentir como ela está distante - ao vê-la a partir de um intermédio. Mas isso não significa uma experiência apenas frustrante. Como a própria Safo descreve, há uma ambivalência. Pois na mesma medida em que se deseja a amada, se está separada dela ("bem perto de estar morta"); há também um prazer na risada atraente que "atordoa" o coração" e um "fogo de pronto" que corre sob a pele de Safo. É na distância que o amor se permite experimentar a partir de uma sensação agridoce. Daí a importância vital do terceiro elemento para Carson.

Mas é importante deixar claro que o terceiro elemento não precisa ser alguém (não precisa ser uma terceira pessoa, objeto de um ciúme). ${ }^{8} \mathrm{O}$ "terceiro elemento" pode ser qualquer coisa desde que esta simultaneamente conecte e separe amante e amado. Um caso que permite pensar outras formas de distância seria o romance Anna Kariênina de Liev Tolstói. Nesse livro, a protagonista Anna Kariênina e o conde Aleksiei Vrónski não apenas se amam como sabem do amor de um pelo outro. Em determinado momento eles inclusive fogem de seus mundos para poderem viver juntos. Invertendo a estrutura tradicional das histórias de amor em que o conteúdo das narrativas é a superação de todos os obstáculos que impedem os amantes de viverem seu amor, o que Tolstói encena são as distâncias que existem mesmo quando os amantes estão juntos. Nesse livro o que impede o amor de se concretizar plenamente, e que figura como um terceiro elemento entre os amados, são os constrangimentos sociais e morais do mundo de Anna Kariênina e Vrónski. Ela era casada, rica e mais velha que Vrónski, e ainda que tenha abandonado sua familia e condição social em nome de seu amor, o tipo de vida que eles levam juntos se torna insuportável para ela. O amor reúne os amantes, mas as consequências nas vidas deles os afastam. Anna Kariênina acaba preferindo o suicidio a ter que viver as implicações daquele amor. O que se vê aí é uma distância que ao mesmo tempo que os afasta é aquilo que eles procuram constantemente atravessar.

Como diz Carson: "O terceiro elemento tem um papel paradoxal, pois ele tanto conecta como separa, marcando que dois não são um, irradiando a ausência cuja presença é exigida por eros" (CARSON, 1998, p. 16, tradução nossa). ${ }^{9}$ Retornando para Safo, isso é visivel em seu fragmento 31, já que é pela conexão intermediada pelo homem, é por meio dele que Safo absorve a presença da sua amada. Ao mesmo tempo, como a amada se dirige a ele e não a ela, a amante é separada do amado.

Com isso em mente, Carson dirá que se trata de uma experiência em que nos deparamos com os limites de nós mesmos a partir da sensação de que algo (alguém) nos falta. Percebemos a nossa existência, existimos, assim como Safo no fragmento 31 referido acima, quando a falta do

\footnotetext{
8 Como é o caso clássico da Recherche proustiana.

9 Do original: The third component plays a paradoxical role for it both connects and separates, marking that two are not one, irradiating the absence whose presence is demanded by eros.
} 
nosso amante nos faz aparecer para nós mesmos ("um tremor / de todo me toma, e mais verde que a relva / estou, e bem perto de estar morta / pareço eu mesma"). O movimento de atração somado a uma experiência de limite constitui os contornos de um "si" que deve ser superado para que o amor se realize. No mesmo momento em que o amante aparece como algo que desejamos, uma falta se desenha em nós e simultaneamente nos desenha enquanto sujeitos. É por conta dessa estrutura que o amor é uma experiência perigosa: amar implica estar disposto a superar nossos limites (perder a si próprio) no exato momento em que tais limites (ou seja, os contornos de nossa subjetividade) se desenham mais claramente.

Mas antes de continuar, é preciso explicar melhor o que significa essa "falta". Não é que eros aponte para uma ausência, um vazio dentro de nós. Trata-se antes de um caráter excedente do sujeito que ama. Se ele se depara com seus limites é porque, paradoxalmente, ele vê alguma forma de realização de si no outro. É por isso que a atenção aos próprios limites que aparece na experiência do amor acaba se tornando também um "dar-se conta" da composição heterogênea dos amantes. Ao amar, um sujeito tem a experiência de ser mais do que uma estrutura atômica fechada em si mesma. Se ele ama é porque, ao mesmo tempo, há algo no outro que fisga e que diz respeito ao amante. Ele é constituido na falta, mas aquilo que falta é apenas o seu excesso.

A experiência de eros depende da sua incompletude constitutiva. Isso acaba implicando para dentro da dinâmica do amor, como Carson ilumina, uma dimensão temporal:

enquanto amante, você procura avançar em direção ao momento no tempo chamado de "depois" em que você vai morder a tão desejada maçã..$^{10}$ Ao mesmo tempo, você está ciente de que, tão logo o "depois" sobrevenha o agora, o momento agridoce, que é seu desejo, vai desaparecer (CARSON, 1998, p. 111, tradução nossa). ${ }^{11}$

Mas o que seria esse desaparecimento do desejo no tempo? Certamente não é o fim da relação - ou melhor, pode até ser, mas o término não é a causa do desaparecimento e sim uma consequência. A questão a que Carson alude parece estar associada ao problema da novidade. Se as relações amorosas são tipicamente retratadas no cinema a partir de uma dinâmica de superação de obstáculos, parece que o problema do tempo aparece quando terminam esses filmes. Depois que as barreiras são superadas, o amor entra em uma nova dinâmica: não se trata mais de simplesmente encontrar seu amado, mas de fazer aquele encontro durar. O filósofo Alain Badiou, em suas discussões sobre o amor, apresenta o problema de forma semelhante. Para ele, há uma dimensão temporal no amor, que diz respeito aos desafios da sua duração:

É necessário entender que o amor inventa uma
forma diferente de durar ao longo da vida. Que
a existência de cada um, pela experiência do
amor, confronta-se com uma nova temporali-
dade. O amor também é, sem dúvida, como diz
o poeta, "o duro desejo de durar". Mais do que
isso, porém, é o desejo de uma duração desco-
nhecida. Porque, como é sabido, o amor é uma
reinvenção da vida. Reinventar o amor significa
reinventar essa reinvenção (BADIOU, 2013, p. 26).

No caso do amor, essa questão temporal aparece, sobretudo, associada à dimensão da novidade, da aproximação de um elemento desconhecido que, com o tempo, vai se tornando conhecido - o que, no caso clássico das relações a dois, assume a forma do tão temido risco de o casal cair na rotina. De modo que podemos dizer que parte do prazer do amor está associado à relação com algo novo ou desconhecido. É algo bem próximo à experiência da pedra de gelo que derrete quando a seguramos na mão, tal como descrito no fragmento de Sófocles que segue abaixo:

\footnotetext{
Essa doença é um mal atrelado ao dia. Aqui está uma comparação - nada mal, eu acho: quando o gelo brilha ao ar livre, crianças pegam.
} 
Cristais de gelo nas mãos são de inicio um prazer bem diferente.

Mas chega um momento você não pode largar a massa derretendo não pode continuar segurando.

O desejo é assim.

Levando o amante a agir e não agir,

de novo e de novo, puxando (RADT, 1977 apud CARSON, 1998, p. 112, tradução nossa). ${ }^{12}$

Esse derretimento do gelo no fragmento é, como a experiência do amor, conflitante. Por um lado, o prazer vem da sensação inicial que se tem ao apertar o gelo; por outro, manter o gelo apertado nas mãos faz com que ele derreta, de modo que, em algum momento, o próprio gelo desapareça por completo. Trata-se de uma situação paradoxal que nos traz um problema: como lidar com algo cujo prazer depende da aproximação, mas cuja mesma aproximação acaba, em um momento seguinte, afastando o prazer? Vemos aqui os mesmos problemas da dinâmica amorosa. Nosso prazer vem da aproximação do objeto amado, mas a concretização radical desse desejo pode acabar destruindo o próprio amor (já que não haveria mais distância que configuraria a relação amorosa).

É para lidar com essa dinâmica conflituosa que Carson vai pensar a ética do amor a partir do conceito de vergonha. Ecoando problemas que aparecem no discurso de Aristófanes em $O$ Banquete (e que não serão desmentidos por Sócrates), a crença em uma anulação das distâncias, em uma fusão, seria antes da ordem da desmedida [hybris] do que a realização plena do amor. Nesse discurso, ele afirma que os seres humanos possuiam no passado uma forma "duplicada". Por conta da sua força, esses humanos teriam se sentido aptos a desafiarem os deuses. Após esse evento, para punir os humanos, Zeus teria decidido partir os seres humanos pela metade, criando assim a forma atual dos seres humanos e explicando a gênese do sentimento de amor que seria uma falta da metade perdida. No final de seu discurso, depois de elaborar os problemas do amor, Aristófanes termina sua fala fazendo um pedido de cautela diante do amor, para que não busquemos nele um tipo de fusão que pode provocar nova desmedida; que cause, assim como na divisão originária, uma nova partilha. Anular a distância é anular o próprio sujeito que é constituído por meio da distância. Mas isso não é tudo, pois a permanência de uma diferença entre os sujeitos amantes em sua tentativa de se fundir acaba produzindo, no máximo, uma proximidade extrema entre amante e amado sem que um se torne o outro. O que faz com que o resultado da tentativa de anulação da distância entre os amantes seja uma situação em que, pela proximidade, se tornem insuportáveis um para o outro. E se tornam frustrados tanto por não conseguirem se fundir, quanto por terem seus limites (cada um com seu "si") ameaçados pela contiguidade extrema de um outro que nunca é efetivamente incorporado. No lugar da fusão desejada, há apenas a esperança de que a fusão seja efetivamente possivel. Na prática, para os amantes que estão envolvidos, qualquer ação que não vá nessa direção é encarada como um sinal de amor insuficiente, qualquer atenção a um terceiro só pode ser lida sob o signo do ciúme. Se a fusão que Aristófanes temia é, na prática, impossivel, a crença de que essa é a forma correta de amar - por meio da anulação absoluta das distâncias - é o suficiente para gerar imensos sofrimentos aos amantes, a ponto de pôr o próprio amor deles em risco.

Com isso em mente, Carson propõe o sentimento da vergonha [aıঠús] como algo que gera um cuidado para manter a distância que afasta esse desejo de que dois se transformem em um. A vergonha não seria um mero temor de ser rejeitado pelo amante. É o momento em que o amante se dá conta da natureza do próprio eros e ele mesmo interpõe uma distância entre ele e o amado: "uma espécie de choque de decoro descarregado entre duas pessoas que se aproximam 
uma da outra pela crise do contato humano, uma sensibilidade instintiva e mútua das fronteiras entre elas. [...] [A] timidez compartilhada que irradia entre amante e amado" (CARSON, 1998, p. 20-21, tradução nossa). ${ }^{13}$ Aqui, porém, nos deparamos com um círculo (mas será ele virtuoso?). Pois se o fim do amor é o que produz temor, encurtar rápido demais as distâncias com o amado para viver esse sentimento pode acabar esgotando os amantes (por tédio, paranóia, frustração e até a descoberta de coisas no amado que seriam mais bem recebidas com o tempo) e tornar essa experiência fugaz. A experiência amorosa se dá no desequilibrio entre uma proximidade que se deseja e as consequências perigosas de se aproximar demais. A vergonha e o decoro com o amado seria uma forma de evitar essa fugacidade. Impõe-se, então, a necessidade de um cuidado complexo que faz aparecer a íntima relação do amor com o tempo. Não se pode aproximar demais do amado, pois pode-se cansar dele (ou ele pode se cansar do amante). Por outro lado, afastar-se demais pode gerar o esquecimento do amado, o que deixa o amante definitivamente distante do seu amor. Ainda que o movimento dos amantes seja sempre em direção a se aproximar dos seus amados, é preciso de distância para amar, já que o fim da distância é o esgotamento do amor. Dessa forma, assim como o espaço é condição de eros - pois é a partir da distância espacial entre amante e amado que aparece o amor -, o tempo é sua condição inversa, aquilo que constantemente ameaça a sua dissolução pois se aproximar rápido demais do amado pode ocasionar uma aceleração da relação amorosa que resulta em um esgotamento do amor antes da hora. O amor, para durar no tempo, precisa de alguma distância entre os amantes.

Se é que é possivel falar em termos de solução, Carson dirá que os amantes não apenas vivem essas distâncias (espaciais e temporais) como, em nome do amor, as perpetuam, as ampliam. Sem a criação de obstáculos - agora pelos próprios amantes, que se desdobram para multiplicar o espaço de novidade - , o amor não teria ocasião de ser vivido de modo duradouro. Em um gesto curioso, tempo e espaço são gerados a partir das necessidades de eros.

É para lidar com essa estrutura que Carson realiza uma estranha reconstrução do diálogo platônico Fedro. O que a autora encontra na figura de Sócrates é alguém que encarna a aceitação do caráter infinito do amor. Se no início do diálogo Sócrates concorda com Lísias sobre o caráter nocivo do amor, eles divergem quanto à solução.

Lísias, como sabemos pelo discurso lido por Fedro, vê a dinâmica agridoce do amor como algo patológico, algo que só produz frustração e sofrimento para os amantes. ${ }^{14}$ Ele não está disposto a entrar no jogo de distâncias em que arriscamos perder nossos limites, em que somos sujeitos a inúmeras dores e sofrimentos. É por isso que, como sublinha Carson, ele procura saltar por cima de toda a distância temporal que existe no amor. Para evitar que "o gelo derreta", ama-se quando já não há mais amor. O que significa que ele apenas se envolve com pessoas que não ama, mas que gosta de modo desapaixonado (sem sair de si). "Lísias se desvia de todo o dilema de eros com um golpe. É um golpe no tempo: ele simplesmente se recusa a entrar no momento que é 'agora' para o homem que ama, o momento presente do desejo" (CARSON, 1998, p. 126, tradução nossa). ${ }^{15}$ Amar sem amar é a solução, se envolver com alguém por quem não se nutre mais do que um apreço agradável. Evita-se a dinâmica da distância anulando-a de fora pra dentro. Ao se posicionar fora do amor, Lísias julga ter resolvido o problema do amor por evitar todo o sofrimento inerente ao jogo do desejo, por evitar todo o trabalho do amor de manutenção do jogo de distâncias.

O que acontece em seguida se desenvolve da seguinte forma: primeiro Sócrates faz um discurso que admite o caráter complicado do amor, seus

\footnotetext{
13 Do original: a sort of voltage of decorum discharged between two people approaching one another for the crisis of human contact. an instinctive and mutual sensitivity to the boundary between them. [...] the shared shyness that radiates between lover and beloved.

14 Cf. Platão, 2016a, 230e-234c.

15 Do original: Lysias sidesteps the whole dilemma of eros in one move. It is a move in time: he simply declines to enter the moment that is 'now' for the man in love, the present moment of desire.
} 
problemas e seus riscos. Em seguida, porém, faz outro discurso, por vergonha do que havia dito primeiramente, já que não consegue aceitar que o amor pode ser algo negativo. É nesse momento que Sócrates efetivamente realiza um elogio ao amor. Mas Carson não se limita a seguir os passos de Sócrates. Ela inverte a estrutura do diálogo platônico, rearranja suas partes e, indo de uma parte a outra do diálogo, reorganiza as diversas imagens evocadas ao longo do texto para reforçar o caráter problemático da "fuga ao tempo".

O rearranjo do texto elaborado pela autora pode ser visto como uma figuração do que ela discute no capitulo "Damage to the living" (CARSON. 1998, p. 130-133), momento em que Carson destaca o elogio à escrita que se apresenta no final de Fedro. E ainda que tenha se tornado um tópico comum na filosofia continental francesa a partir de Jacques Derrida (2005) comentar as criticas à escrita feitas por Platão ${ }^{16} \mathrm{com}$ tom de decepção, Carson lembra que, no diálogo platônico, a crítica é à escrita que perdeu qualquer semblante de vida. Se o logos é associado à fala, isso é feito na medida em que

em sua forma falada ele é um processo de pensamento vivo, cambiante e único. Ele acontece uma vez e é irrecuperável. O logos escrito por um escritor que conhece sua arte vai se aproximar desse organismo vivo a partir da necessária ordenação e interrelação das suas partes: "organizado assim como um ser vivo, tendo ele mesmo uma espécie de corpo, de modo a não ser desprovido de pé e nem de cabeça, mas ter partes médias e finais, escritas adequando-se umas às outras também ao todo" (PLATÃO, 2016a, 264C) (CARSON, 1998, p. 132, tradução nossa). ${ }^{17}$

Não surpreende que a própria autora se ponha a rearranjar a ordem do discurso platônico para revelar o problema que lhe concerne: a relação entre amor e tempo.

O problema de Lisias e de Sócrates, é preciso lembrar, é o mesmo. Ambos partem dos efeitos negativos que a dinâmica da distância produz nos amantes, nos sofrimentos que vivem em nome do amor. Como vimos, trata-se de uma questão que põe no centro a experiência do tempo. ${ }^{18}$ Mas deve-se admitir que esse problema não aparece de modo imediato no diálogo. Se, como Sócrates e Carson põem em relevo, a boa escrita possui uma ordem, é apenas como efeito do rearranjo carsoniano do Fedro que a relação dessa questão com o amor parece vir à tona. Isso será feito a partir da retomada sequencial de três imagens que, na forma corrida do diálogo, estão espalhadas em pontos diversos. Essas imagens têm como função indicar estratégias diferentes para lidar com o problema do amor. Ainda que essas estratégias todas fracassem, por razões explicadas por Carson, o que resulta dessa operação, porém, é a percepção de que há mais no diálogo do que se costuma ler nele. Se habitualmente se pensa esse texto a partir do problema do amore da escrita - mas sempre com uma dificuldade de compreender a integração desses dois problemas no contexto do diálogo - , Carson faz o diálogo aparecer de uma forma renovada quando mostra a centralidade do problema do tempo e sua relação essencial com o amor.19 É como se olhássemos com novos olhos um velho alvo de afeição, reproduzindo nesse gesto o mesmo tipo de negociação temporal que os amantes precisam encarar para que seu amor não se esgote.

No rearranjo carsoniano, a primeira dessas estratégias é pensada a partir da história da ins-

\footnotetext{
16 "Pois há algo de terrivel na escrita, Fedro, e que se assemelha realmente à pintura. Pois os produtos desta estão postos, como seres vivos, mas, ao interrogá-los sobre algo, mantêm-se em silêncio solene. E o mesmo se dá com os discursos: parecerá a ti que falam pensando por si mesmos, mas, ao interrogá-los querendo aprender sobre o que quer que tenham dito, indicam sempre uma única e mesma coisa" (PLATÃO, 2016a, 275d)

${ }_{17}$ Do original: in its spoken form is a living, changing, unique process of thought. It happens once and is irrecoverable. The logos written down by a writer who knows his craft will approximate this living organism in the necessary ordering and interrelation of its parts: 'organized like a live creature with a body of its own, not headless or footless but with middle and end fitted to one another and to the whole.' (264c). ${ }_{18}$ "Ambas as teorias concordam que o desejo leva o desejante a uma relação paradoxal com o tempo. Ambas as teorias observam que o erastēs lamante] convencional, lida com esse problema com certas táticas, procurando bloquear os desenvolvimentos físicos e pessoais que estão carregando seu amado pela vida. Essas táticas são nocivas, Sócrates e Lísias concordam; eles não concordam sobre quais táticas são mais indicadas." (CARSON, 1998, p. 137, tradução nossa). Do original: Both theories observe that the conventional erastēs responds to this problem with certain tactics, attempting to block the natural currents of physical and personal development that are moving his beloved through life. These tactics are damaging. Sokrates and Lysias concur; they do not concur at all on what tactics are preferable. 19 Sem contar que, ao pôr o problema do tempo no centro do diálogo, Carson consegue amarrar o problema da escrita com o do amor. uma integração que sempre foi um desafio enorme para os leitores desse texto.
} 
crição que teria sido escrita no epitáfio do túmulo de Midas (PLATÃO, 2016a, 264C-264e). O que será apontado a partir do destaque a essa imagem são os problemas do discurso de Lísias. No diálogo, Sócrates compara a estrutura sem vida do discurso de Lísias ao que está inscrito no epitáfio de Midas. Nele, os versos podem ficar em qualquer ordem sem que qualquer diferença se produza, indicando não apenas a falta de vida, mas a falta de sentido, de modo que "como o não amante de Lísias, as palavras da inscrição permanecem desconectadas do tempo e declaram sua diferença do mundo dos seres efêmeros" (CARSON, 1998, p. 135, tradução nossa). ${ }^{20}$ Se a escrita de Lisias é morta, é porque a ordem não faz diferença, como no exemplo mencionado. A inscrição de Midas aparece, portanto, como imagem de um tipo de estratégia na relação amorosa que procura resolver o sofrimento do tempo ao se situar fora do tempo. Essa equivalência entre ausência de ordem e saida para fora do tempo, porém, torna mais visivel ainda o que se entende por distância. Não se trata apenas de uma separação que se procura superar, mas também da relação amorosa como um tipo de percurso que ganha sentido em uma duração especíica, no contato com determinados obstáculos e em determinadas sequências - assim como o bom logos, que se organiza como um ser vivo. A relação amorosa é, assim, algo que se dá e se faz enquanto história. De modo que se não faz diferença, se não há nenhuma distância que marque o espaço entre os amantes, não há propriamente relação amorosa, há apenas um girar em falso em que se mantém nos limites do "si mesmo" que pode, quando muito, dar uma estabilidade agradável aos amantes. E é justamente esse tipo de diferença que Carson marca ao rearranjar o Fedro. Ela não apenas mostra que esse livro se altera conforme sua ordem, como também consegue, como falamos, se apresentar algo de diferente sobre o problema a partir dessa releitura.
A segunda imagem mobilizada também aparece muito brevemente após o longo segundo discurso de Sócrates sobre o amor, mas antes da imagem do túmulo de Midas: o mito das cigarras. O objetivo de Carson ao destacar essa passagem é apresentar uma segunda estratégia para lidar com os problemas do amor. Nesse caso, explora-se a possibilidades dos amantes habitarem plenamente o "momento do agora" do amor, do qual fogem os partidários de Lísias e Midas. ${ }^{21}$

Após o discurso de elogio ao amor proferido por Sócrates e os elogios de Fedro a esse discurso, realiza-se uma transição da discussão do tema do amor para uma análise da escrita e da retórica. Mas se a transição é curta (ocupando não mais que algumas páginas), há alguns elementos nela que, uma vez explicitados, nos permitem ver em que medida essa imagem aparentemente casual estaria jogando com o tema do amor em sua relação com o tempo.

No caso, a mudança de assunto ocorre após Fedro elogiar a qualidade literária do discurso de Sócrates. Passando para um comentário sobre bons e maus discursos, Sócrates perguntará:

Temos alguma necessidade, Fedro, de interrogar a fundo sobre tudo isso Lisias ou qualquer outro que em algum momento tenha escrito ou venha a escrever, quer uma composição politica, quer privada, seja em metros como poeta, seja sem metros como um leigo? (PLATÃO, 2016a, 258d-258e).

Ao que o Fedro responde: "Pergunta se temos necessidades? E em vista de que alguém viveria, por assim dizer, se não por prazeres desse tipo?" (PLATÃO, 2016a, 258d-258e). Sócrates responde a isso falando "Há tempo para o ócio, ao que parece" (PLATÃO, 2016a, 258d-258e). Ele observa então as cigarras e se pergunta sobre o que elas achariam do que eles fazem e emenda com um suposto mito de origem delas. O que há de interessante nesse mito sobre como se originaram as cigarras é (como sublinha Carson) que elas

\footnotetext{
20 Do original: Like Lysias' nonlover, the words of the inscription stand aloof from time and declare their difference from the world of ephemeral beings.

${ }_{21}$ "Elas las cigarras] realizam uma forma mais nobre desse dilema [erótico] do que a realização de Midas, pois sua paixão é musical, e elas oferecem uma nova solução ao paradoxo do amante de um "agora" e de um "depois". As cigarras simplesmente adentram o 'agora' de seu desejo e permanecem ali" (CARSON, 1998, p. 139, tradução nossa). Do original: They are creatures pulled into confrontation with time by their own desire. They enact a nobler version of this dilemma than Midas did, for their passion is musical, and they offer a new solution to the lover's paradox of 'now' and 'then.' The cicadas simply enter the 'now' of their desire and stay there.
} 
provêm de seres humanos que decidiram viver no "agora", do amor às artes, a ponto de esquecerem de se alimentar e de se hidratar. ${ }^{22}$ Em troca, como um presente, as Musas fizeram que deles nascesse uma raça de animais, as cigarras, que passam a vida sem nunca precisar se preocupar com alimentação ou bebidas, cantando até morrer às suas Musas, até que, após a morte, "para junto das Musas vão anunciar a cada uma por quem são honradas aqui" (PLATÃO, 2016a, 259c).

A segunda estratégia discutida por Carson seria, portanto, uma espécie de sacrificio explícito ao prazer do agora. Pois enquanto o não amante Lisias "sacrifica o prazer intenso e contingente do 'agora' do amado por um período estendido de um 'depois' com emoções consistentes e comportamentos previsiveis" (CARSON, 1998, p. 139, tradução nossa), ${ }^{23}$ as cigarras, por outro lado, "investem toda a sua vida no deleite momentâneo do 'agora'. O tempo que dura e as suas transições não as afetam. Elas se encontram presas em uma vivência mortal do prazer" (CARSON, 1998, p. 139, tradução nossa). ${ }^{24}$ Em suma, se por um lado elas não recusam os paradoxos do amor, no fim, elas só podem optar por ele na medida em que foram agraciadas pelos deuses, pois como diz Carson, "são criaturas que preferiram declinar o estatuto humano por achar sua condição incompativel com seu desejo pelo prazer. [...] Uma escolha que não existe para seres humanos, nem qualquer outro organismo que está a viver no tempo" (CARSON, 1998, p. 139-140, tradução nossa)25. O que isso significa é que a escolha das cigarras é uma escolha que retira elas dessa dinâmica temporal pautada pelo jogo entre um "agora" e um "depois". Ao abrir mão dessa dialética em prol de um de seus polos, renuncia-se àquilo que constituiria o sujeito que ama. Ou seja, um sujeito (e, no caso, o ser humano) seria justamente constituido a partir das distâncias encenadas na relação amorosa, um aqui e um ali, ou um agora e um depois. Na ausência desses polos, não seria possivel falar de amor, mas no máximo de um desejo, pois o amor é justamente a experiência que aparece com esse paradoxo. Ao se evitar o paradoxo, como no caso da primeira estratégia, evita-se também o amor.

Mas há algo mais a se dizer sobre esse interlúdio. Ainda que essa estratégia das cigarras não possa ser adotada por nós, visto que não fomos agraciados com essa dádiva divina (e nem gostariamos de ter sido, pois significaria que não existiriamos como somos), há algo nela que nos permite começar a compreender como é possivel negociar melhor as distâncias do amor. Se voltamos ao inicio da história (que propositalmente passamos rápido demais), podemos observar que Sócrates repara nas cigarras justamente para saber o que elas achariam deles gastarem o tempo discutindo filosofia:

E tenho também a impressão de que, a cantar
no auge do calor e por sobre nossas cabeças,
conversando umas com as outras, as cigarras
nos olham lá de cima. Se vissem então nós dois,
em vez de conversar, a tirar um cochilo seduzidos
por elas, em pleno meio-dia - tal como a maioria,
por conta da preguiça de pensar -, zombariam
com justiça de nós, imaginando que escravos
quaisquer vieram até este retiro para repou-
sar, tal como cordeiros fazendo a sesta junto a
uma fonte. Mas, pelo contrário, se nos vissem a
conversar ea navegar inflexiveis ao largo delas
como de Sereias, admiradas talvez dessem o
presente que obtiveram dos deuses e têm a
dar aos homens (PLATÃO, 2016a, 258 e-259b).

Elas julgariam mal os homens em caso de descanso. Mas se eles estivessem conversando sobre filosofia, era possivel que as cigarras dessem aos homens o dom que thes fora concedido pelos deuses, ou seja, o de poder viver integralmente na sua arte.

Aqui, porém, tem algo ambíguo. Pois é óbvio que a vida das cigarras não é plenamente desejável, já que viver dessa forma é o que também encurta as suas vidas. Por outro lado, a filosofia e

\footnotetext{
22 "Nascidas as Musas e revelado assim o canto, alguns deles foram então de tal modo arrebatadas por esse prazer a ponto de, cantando, descuidarem da comida e da bebida, vindo a falecer" (PLATÃO, 2016a, 259b-259c).

23 Do original: sacrifices the intense and transient pleasure of the lover's 'now' in return for an extended 'then' of consistent emotion and predictable behavior.

24 Do original: Cicadas choose the opposite sacrifice, investing their whole lives in the momentous delight of 'now.' Passing time and its transitions do not affect them. They are stranded in a living death of pleasure.

25 Do original: they are creatures who were once men but who preferred to decline from human status because they found man's condition incompatible with their desire for pleasure. [...]. It is not a choice open to human beings, nor to any organism that is committed to living in time.
} 
as outras artes aparecem como algo tão desejável que um encurtamento da vida ao tomá-las como práticas exclusivas poderia até ser uma ocasião para os humanos serem honrados pelas Musas. A filosofia aparece, portanto, como uma espécie de luxo, um suplemento, mas um suplemento que dignifica a vida, mesmo que a custo de danificá-la.

Ainda que não possamos viver da filosofia (essas já foram as cigarras, que, para seguirem vivendo disso, passaram a ter outro tipo de vida, como marca Carson), entrar na filosofia seria o momento em que, de alguma forma, entramos na graça dos deuses, ainda que não possamos suportar esse modo de vida continuamente. Estar próximo desse elemento divino é, portanto, de alguma forma ser tocado pela figura do eterno, do que está fora do tempo da nossa duração, sem ser esmagado por ela e perder os limites que nos compõem enquanto sujeito. ${ }^{26}$ Vemos aqui um caminho para lidar com o problema do amor e do tempo que será desenvolvido por Carson em um momento posterior do seu livro, visto que, para ela, nas demandas impossiveis do amor está o próprio problema da nossa relação com a eternidade, ou seja, com algo que transcende a nossa finitude. De modo que, se o amor é um problema, lidar com ele passaria também por uma possibilidade de negociar com as demandas e distâncias impossiveis do eterno a partir do ponto de vista da finitude. Não apenas do que a finitude permite compreender, mas do que ela é capaz de aguentar sem se perder diante do infinito.

A terceira imagem evocada por Carson no rearranjo do diálogo platônico é a imagem dos rituais de jardinagem em homenagem ao deus Adonis, uma imagem que aparece no final do texto, quando se realiza a crítica à escrita. Platão compara a escrita a esses rituais de jardinagem que fariam as sementes germinarem fora de seu tempo em apenas alguns dias. Ainda que se consiga acelerar o processo de germinação, isso não vem sem custo. Costuradas em potes e sem raízes, essas sementes, tão logo floresciam, já morriam no dia seguinte ao fim do festival. A partir dessa imagem podemos ver a terceira estratégia que Carson põe em relevo para se lidar com os problemas do amor. Esse tipo de amante procura acelerar o próprio tempo, "começando onde deveria terminar e obtendo suas intenções por meio de um atalho violento dos estágios iniciais do amor" (CARSON, 1998, p. 143, tradução nossa). ${ }^{27}$ Mas como isso funciona na prática? Como essa estratégia evitaria os dramas do amor se ainda se atravessa o "agora" em direção ao "depois"? A resposta para isso está na caracterização do festival como uma "brincadeira", já que um jardineiro experiente, interessado na sobrevivência de seu jardim, apenas realizaria tal tipo de jardinagem "por ocasião de uma festividade e divertimento" (PLATÃO, 2016a, 276b). O terceiro tipo de estratégia, portanto, só seria possivel por não ser uma relação amorosa séria. Como diz Carson, "assim Sócrates descreve as tendências manipulativas do erastēs [amante] convencional. Esse amante prefere jogar seus jogos eróticos com um parceiro que não tem nem raizes nem futuro" (CARSON, 1998, p. 144, tradução nossa). ${ }^{28} \dot{E}$ isso que permite a ação manipulativa dos amantes mais experientes - e é isso que acaba vingando nas relações amorosas criticadas no diálogo (tanto por Sócrates, como por Lísias). Para que sejam relações friamente manipuláveis, isentas de frustração, elas devem carecer de algo que torne as distâncias relevantes. Ou seja, falta eros, como aquilo que faz com que essas distâncias entre um "agora" e um "depois" não sejam quaisquer distâncias, mas que possuam algum significado.

Em todas essas imagens e estratégias evocadas, há uma tentativa de resolver o paradoxo do amor. Na primeira imagem procura-se evitar o tempo a partir da rejeição do "agora" em nome do "depois". Na segunda imagem vemos o inverso, recusa-se o "depois" em proveito do "agora". Em ambos os casos a dinâmica temporal é dissolvida

26 Mas também sem ser, como no caso do "não amante", alguém que evita sofrimentos por simplesmente se recusar entrar no jogo do amor.

27 Do original: which starts where it should end and achieves its rhetorical and conceptual purposes by a violent shortcut through the beginning stages of love.

28 Do original: So Sokrates describes the manipulative tendencies of the conventional erastēs. This lover prefers to play his erotic games with a partner who has neither roots nor future. 
pela escolha de um dos polos. No caso dessa terceira imagem, falta o próprio elo que une os dois amantes e que dá sentido a essas distâncias, já que ela é vivida apenas como um jogo.

A passagem por essas imagens nos permite entender melhor o que está em jogo nas tentativas de lidar com o amor e porque Lísias é um adversário digno de ser enfrentado (a ponto de ter tanto espaço no diálogo, mesmo que por meio de um discurso cheio de furos). Se Sócrates se preocupa com a posição de Lísias, é porque ele promete justamente aquilo que não temos quando nos vemos imersos em uma relação amorosa e que aparece como causa de inúmeros sofrimentos: controle. ${ }^{29}$ Ao escolher se posicionar fora do tempo, o que ele promete aos amantes é uma experiência que os ajuda a evitar os delirios do amor. Nos manteriamos senhores de nós mesmos, não seriamos escravizados pela paixão. Mas de novo, isso só é possivel pelo fato de Lisias ignorar o começo da experiência do amor.

É por isso que Sócrates irá fazer não um, mas dois discursos. Falta na experiência de Lísias algo que falta também ao seu discurso, o momento inicial, o momento em que o amor aparece e torna alguém um amante. Ou seja, o momento em que alguém se apaixona. Não à toa, como Carson marca na sua avaliação do início do discurso de Lísias, Sócrates pede três vezes para Fedro repetir seu inicio: "E releia para mim o começo do discurso de Lísias" (PLATÃO, 2016a, 262d). "Queres reler o começo dele de novo para nós?" (PLATÃO, 2016a, 263e) e "Lê, para que eu possa ouvi-lo dele mesmo" (PLATÃo, 2016a, 263e). Essa insistência não é apenas uma critica ao discurso pobre de Lísias, mas ao fato de que o elemento que dá sentido à relação amorosa está ausente. Se Lísias consegue falar de um "depois", isso é possivel apenas por ele evitar o elemento do amor que foge ao nosso alcance: o fato de que não escolhemos nos apaixonar. Se não escolhemos nos apaixonar, não é possivel decidir se posicionar fora do tempo.
É por isso que as três estratégias mencionadas podem no máximo ser falsas soluções para um falso problema, já que resolver os paradoxos do amor é sair do próprio amor.

Após esse rearranjo, podemos entender melhor a própria posição de Sócrates. Sendo um partidário de Eros, ele enxerga o amor como a ocasião em que o infinito se impõe entre os amantes a ponto de dar sentido a uma história, momento em que as distâncias aparecem como distâncias relevantes e que devem ser encaradas - ainda que insuperáveis em um sentido absoluto (ou seja, sem que possam ser anuladas). Com isso em mente, não existe a possibilidade de se posicionar no "depois", no "antes", ou mesmo apenas "brincar de amor", pois essas distâncias só aparecem verdadeiramente quando nos apaixonamos. E quando nos apaixonamos já é tarde demais. "Como Sócrates diz, sua história começa no momento em que Eros entra em você. Essa incursão é o maior risco na sua vida. Como você lida com ela é um indice da qualidade, da sabedoria e do decoro das coisas que existem dentro de você" (CARSON, 1998, p. 152, tradução nossa)..$^{30}$ Mas além disso, há algo de divino nessa relação, como o próprio discurso de Sócrates diz, ao chamar o amor de uma loucura divina, pois

[...] para Sócrates, o momento em que eros
começa é um vislumbre do 'começo' imortal
que é a alma. O 'agora' do desejo é uma haste
imerso no tempo que emerge no sem-tempo
[timelessness], onde deuses flutuam, regozi-
jando-se na realidade (CARSON, 1998, p. 157 ,
tradução nossa). ${ }^{31}$

Divino, porém, não é aqui uma referência simplesmente a um conteúdo teo/mitológico específico. O divino é justamente o espaço em que o eterno/infinito adentra o temporal/finito. $\mathrm{O}$ amor, ao nos tirar de nós mesmos em direção a outro, nos permitindo visibilizar as distâncias que compõem o amado e o amante, seria justamente essa ocasião.

Se o tempo e espaço são gerados a partir do

29 "O texto de Lísias oferece aos seus leitores algo que ninguém que houvesse amado poderia deixar de desejar: autocontrole" (CARSON, 1998, p. 147, tradução nossa).

30 Do original: As Sokrates tells it, your story begins the moment Eros enters you. That incursion is the biggest risk of your life. How you handle it is an index of the quality, wisdom and decorum of the things inside you.

${ }_{31}$ Do original: For Sokrates, the moment when eros begins is a glimpse of the immortal 'beginning' that is a soul. The 'now' of desire is a shaft sunk into time and emerging onto timelessness, where the gods float, rejoicing in reality. 
amor, isso implica que para Carson o amor não é deste mundo. Ele é o que aparece como o que bagunça o nosso senso de localização dessas coordenadas e que faz com que elas de fato importem. O tempo e espaço seriam produtos de uma sensibilização pelo amor enquanto distância entre os amantes - ou seja, tempo e espaço percebidos, compreendidos, sentidos em sua singularidade na medida em que constituem uma zona erótica que relaciona amantes. $\mathrm{O}$ amor, ao tirar do eixo nossa experiência corriqueira, dá sentido ao tempo, fornece uma ordem, constitui uma história. Da mesma forma que um bom texto depende da sua ordenação, a própria vida se ordenaria a partir do amor. O tempo em que se espera o amado retornar de uma viagem é que faz com que ele seja vivido. Pode-se dizer que o tempo passa a ser organizado a partir dessa bagunça que é o amor que irrompe sem ser chamado.

Isso não significa, porém, que tudo se resolve. Pois se eros é a irrupção do infinito no finito, isso não nos torna automaticamente infinitos, deuses. Somos, ainda, mortais. E isso implica a existência de uma opacidade sobre o que é essa força que nos atravessa. Também não é o caso de afirmar que a experiência de eros se perde no infinito. ${ }^{32}$ Pois, como seres finitos, esse infinito não deixa de ser em algum momento finitizado pela realização do amor. Se o amor tem sentido é porque em algum momento (invisivel para quem está atravessando essas distâncias na relação amorosa) essa virtualidade infinita colapsa na atualidade de uma relação amorosa que decorre em um periodo de tempo finito. ${ }^{33}$

A opacidade aparece quando Carson vai comentar um par de versos citados por Sócrates em seu segundo discurso sobre o amor:

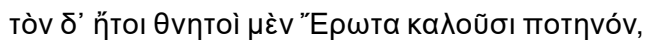

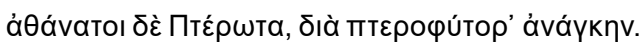

Os mortais por certo o chamam de Eros volátil [alado],

mas os imortais de Pteros por força de asas dar (PLATÃO, 2016a, 252b). ${ }^{34}$

Essa diferença entre nome dos mortais e dos deuses não é apenas uma diferença nos predicados, embora essa diferença exista. A linguagem dos deuses seria ela mesma mais real que a linguagem humana, pois ela não apenas descreve uma experiência (como é o caso da humana), como também dá conta da razão de ser daquela experiência (sua causa). No caso mencionado é visível um ganho semântico que se têm na passagem de

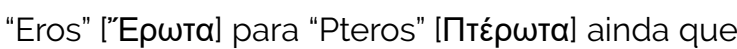
não seja totalmente inteligivel essa diferença. ${ }^{35}$

A diferença semântica aparece a custo de quebra da métrica do segundo verso. Nesse verso, é justamente a presença do 'Pt' [Пт], como marcador da diferença entre a linguagem humana e divina, que produz uma métrica que até Sócrates admite ser "um tanto irregular" (PLATÃO, 2016a, 252c). O verso, um hexâmetro datílico, respeita a métrica perfeitamente, salvo na palavra "de" [ठغ̇], como pontua Carson (1998, p. 162). O conflito aparece por conta das regras da prosódia grega. Caso a

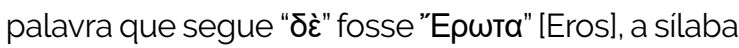
seria curta e simples, respeitando a exigência que naquele local haja uma silaba curta, fazendo com que a métrica seja respeitada. O problema é que segundo essas regras, sílabas curtas se tornam longas quando são seguidas por duas consoantes, que é o caso do "Пт" que existe no início da palavra Пте́ршта [Pteros]. Esse "Пт", porém, é exatamente

\footnotetext{
Agradeço ao Gabriel Tupinambá por essa lembrança.

33 O que revela no seu avesso uma patologia: a crença de que um ser finito pode sorver essa experiência infinita sem a mediação finita

4 Na tradução de Carson (1998, p. 161) sua argumentação fica mais visivel: "Now mortals call him winged Eros / but immortals call him Pteros, because of the wing-growing necessity".

35 "A tradução é inepta pois o tradutor não sabe o que ele significa. A frase nos providencia de maneira ostensiva com um aitia Icausa reall divino para o verdadeiro nome de Eros. Mas de quem são as asas e de quem é a necessidade? Será Eros que tem asas? Será que Eros precisa de asas? Será que Eros causa de que outros tenham asas ou tenham necessidade de asas? Será que Eros precisa fazer com que outros tenham asas? Será que Eros precisa causar os outros a precisarem ter asas? Várias possibilidades, não incompativeis umas com as outras, emergem dessa citação épica. É possivel que em seu modo de aprimorador que os deuses pretendem implicar toda essas possibilidades ao mesmo tempo quando usam o nome Pteros. Mas nós não podemos saber isso." (CARSON, 1998, p. 163, tradução nossa). Do original: The translation is inept because the translator does not know what it means. This phrase ostensibly supplies us with a divine aitia for the true name of Eros. But whose are the wings and whose is the necessity? Does Eros have wings? Does Eros need wings? Does Eros cause others to have or to need wings? Does Eros need to cause others to have wings? Does Eros need to cause others to need to have wings? Various possibilities, not incompatible with one another, float out from the epic quotation. It is arguable that in their enhancing way the gods mean to imply all the possibilities at once when they use the name Pteros. But we cannot know that.
} 
aquilo que marca a diferença entre a linguagem divina e a humana. Essa bagunça não é por acaso. De modo que há um dilema na estrutura desses versos: "de não pode ser uma silaba longa e uma silaba curta ao mesmo tempo, ao menos não na realidade como a vemos" (CARSON, 1998, p. 162, tradução nossa). ${ }^{36} \mathrm{~A}$ bagunça na métrica pode ser lida, então, como o momento em que o elemento divino aparece a nós. Não como uma harmonia, mas justamente por apontar um tipo de harmonia que só poderia ser visivel ao próprio divino, já que na linguagem divina deve ser possivel que a silaba seja longa e curta ao mesmo tempo nesse verso. ${ }^{37}$ Para nós há apenas uma espécie de opacidade que não se resolve.

Por que isso é importante? Porque, do ponto de vista da finitude, o amor é um problema; "se apaixonar, parece, desloca suas prioridades. Sucedem comportamentos aberrantes. As regras de decoro caem por terra. Essa é a experiência comum (pathos) dos amantes, diz Sócrates, que os homens chamaram de Eros (252b)" (CARSON, 1998, p. 160, tradução nossa). ${ }^{38}$ Do ponto de vista da finitude, o amor só pode aparecer como incômodo. Ao trazer o verso com métrica irregular, Sócrates poderia estar apontando para uma dimensão opaca no próprio amor. Há um estranhamento causado nessa irrupção do infinito, mas por sua natureza infinita, não conseguimos dimensioná-lo adequadamente. O que parece acontecer é que essa intrusão gera o processo de sensibilização das distâncias que se fazem distâncias, como descrevemos acima. O amor é, em certo sentido, o próprio movimento de atenção às distâncias.

Mas, é preciso lembrar, os versos são escritos, as palavras são lidas (sem que a estranheza da linguagem infinita dos deuses seja completamente domesticada). De modo que se ocupa ao mesmo tempo duas posições na relação amorosa: uma em que a história se realiza na duração temporal (a duração da vida, em que nos movemos nem sempre sabendo o que nos move) e outra em que ela aponta para seu aspecto eterno. Nem sempre compreendemos o que se passa nesse campo, o que faz com que os amantes persistam (pois, do ponto de vista terreno, as frustrações podem se acumular). Mas é possivel dizer que aquilo que nos estimula a continuar vivendo o jogo das distâncias amorosas, mesmo quando parecem faltar razões claras para insistir, é justamente o lado eterno do amor que nos determina enquanto amantes. Esse segundo aspecto do amor permanece estranho, pois opaco. Não conseguimos habitar essa segunda perspectiva que se abre no amor plenamente, visto que somos finitos, mas a experiência do amor passa justamente pela experimentação desse impulso que transcende a nossa finitude e que é a razão do começo de qualquer história de amor. Essa, assim, é a maneira como Sócrates parece lidar com - e não resolver - os paradoxos do amor.

Essa opacidade, porém, não é uma cegueira. Ela é um efeito da nossa constituição finita. Mas é nesse ponto também que se torna visivel a relação entre o amor e a filosofia, que traz Carson para junto de Platão. Se o amor é uma certa forma de atenção às distâncias, fica mais claro em que medida o movimento em direção ao saber se relaciona com o amor. A condição da filosofia é o próprio não saber, a existência de uma certa zona de desconhecimento que impulsiona o conhecimento (como Platão descreve em $O$ Banquete). Não se trata de um desconhecimento absoluto, porém. Daí a importância do espanto e que a opacidade se apresente inicialmente como opacidade. Trata-se sempre de um não saber que se apresenta como não saber, que sensibiliza a distância entre um desconhecimento e o conhecimento e nos impele a percorrer essa distância: "nós pensamos ao projetar o mesmo na diferença, ao aproximar coisas por meio de uma relação ou uma ideia enquanto ao mesmo tempo mantemos as distinções entre elas" (CARSON, 1998, p. 171,

36 Do original: De cannot be both a long syllable and a short syllable at the same time, at least not in reality as we see it.

37 "As asas de Eros marcam uma diferença critica entre deuses e humanos, pois elas extrapolam a expressão humana. Nossas palavras são pequenas demais, nossos ritmos restritos demais." (CARSON, 1998, p. 163, tradução nossa). Do original: Eros wings mark a critical difference between gods and men, for they defy human expression. Our words are too small, our rhythms too restrictive."

38 Do original: Falling in love, it seems, dislocates your view of what is significant. Aberrant behavior ensues. Rules of decorum go by the wayside. This is the common experience (pathos) of lovers, Sokrates says, to which men give the name Eros. 
tradução nossa). ${ }^{39}$ Seriam justamente esses, como marca Carson, o saber e o amor de Sócrates: "uma capacidade de ver a diferença entre aquilo que se conhece e o que se desconhece" (CARSON, 1998, p. 172, tradução nossa). ${ }^{40}$

Mas não seria esse "desconhecimento" justamente a distância (estranha, divina) que se interpõe na situação erótica? A irrupção do infinito no finito é justamente aquilo que ao mesmo tempo nos escapa (e que, enquanto seres finitos, não podemos dar conta), nos fisga em uma relação a dois. Somos capturados pelos nossos excessos, que têm seus caráteres excedentes visibilizados na distância que aparece entre um amante e seu amado. Filosofia e erótica estariam, portanto, inevitavelmente entrelaçadas, sem, por isso, serem a mesma coisa. Não chega a surpreender que a própria relação entre a filosofia e o amor seja também uma performance de Eros.

O amor acaba sendo justamente aquilo que nos permite algum grau de clareza ao nos pôr diante do eterno. Isso acontece pois, se o amor depende das distâncias entre amantes, pode-se dizer que o momento em que elas se fazem relevantes, que se apresentam como obstáculo, é simultaneamente o momento em que elas se fazem visiveis, que passam a ser objeto da sensação e da percepção. Mas como vimos, essas distâncias são elas mesmas produtos do amor, ou seja, de algo de outro mundo. É por isso que se pode dizer que, como Carson afirma, que os amantes estão envolvidos em "um clima de saber que flutue sobre toda a sua vida", de modo que "você parece saber o que é real e o que não é." (CARSON, 1998, p. 153, tradução nossa). ${ }^{41}$ O amor ao saber e o saber do amor se confundem, pois o que se sabe é justamente o espaço entre os amantes, aquilo que verdadeiramente importa e que cabe aprender a negociar.

\section{Referências}

BADIOU, Alain. Elogio ao amor. São Paulo: Martins Fontes, 2013.

BAUMAN, Zygmunt. Amores liquidos. Rio de Janeiro: Jorge Zahar, 2004

CARSON, Anne. Eros, the bittersweet. Champaign: Dalkey Archive, 1998.

D'ANGOUR, Armand. Socrates in love. Londres: Bloomsbury Publishing, 2019

DERRIDA, Jacques. A farmácia de Platão. São Paulo: Iluminuras, 2005

FREUD, Sigmund. Observações psicanaliticas sobre um caso de paranoia relatado em autobiografia ("O caso Schreber"), artigos sobre técnica e outros textos (19111913). São Paulo: Companhia das Letras, 2010.

FREUD, Sigmund. Observações sobre um caso de neurose obsessiva ("O homem dos ratos"), uma recomendação de infância de Leonardo da Vinci e outros textos (1909-1910). São Paulo: Companhia das Letras, 2013.

ILLOUZ, Eva. Why love hurts. Cambridge: Polity Press, 2012.

LACAN, Jacques. O seminário, livro 8. Rio de Janeiro: Jorge Zahar, 1992.

PLATÃo. Fedro. São Paulo: Penguin Classics Companhia das Letras, 2016.

PLATÃO. O Banquete. São Paulo: Editora 34, 2016.

SAFO DE LESBOS. Hino a Afrodite e outros poemas. São Paulo: Hedra, 2011.

\section{Rafael Saldanha}

Doutor em Filosofia pela Universidade Federal do Rio de Janeiro (UFRJ), no Rio de Janeiro, RJ, Brasil. Pesquisador independente, no Rio de Janeiro, RJ, Brasil.

\section{Endereço para correspondência}

Rafael Saldanha

Universidade Federal do Rio de Janeiro

Largo São Francisco de Paula, 1, Prédio do IFCS, sala 101

Centro, 20051-070

Rio de Janeiro, RJ, Brasil

Os textos deste artigo foram revisados pela Poá Comunicação e submetidos para validação do autor antes da publicação.

39 Do original: we think by projecting sameness upon difference, by drawing things together in a relation or idea while at the same time maintaining the distinctions between them. Continua a citação: "Uma mente pensante não é engolida pelo que ela vem a conhecer. Ela se estende para alcançar algo relacionado a ela mesma e ao seu conhecimento atual (e, portanto, conhecivel em certa medida) mas também separado dela mesma e de seu conhecimento atual (não idêntico a eles). Em qualquer ato de pensamento, a mente deve se estender nesse espaço entre conhecido e desconhecido, ligando um ao outro, mas mantendo visivel suas diferenças" (CARSON, 1998, p. 171, tradução nossa). Do original: A thinking mind is not swallowed up by what it comes to know. It reaches out to grasp something related to itself and to its present knowledge (and so knowable in some degree) but also separate from itself and from its present knowledge (not identical with these). In any act of thinking, the mind must reach across this space between known and unknown, linking one to the other but also keeping visible their difference.

40 Do original: A power to see the difference between what is known and what is unknown constitutes

41 Do original: A mood of knowledge floats out over your life. You seem to know what is real and what is not. 